\title{
LPS Upregulated VEGFR-3 Expression Promote Migration and Invasion in Colorectal Cancer via a Mechanism of Increased NF-KB Binding to the Promoter of VEGFR-3
}

\author{
Guangwei Zhu $u^{a, b}$ Qiang Huang ${ }^{a, b}$ Wei Zheng ${ }^{a, b}$ Yongjian Huang ${ }^{a, b}$ Jin Hua $a^{a, b}$ \\ Shugang Yang ${ }^{a, b}$ Jinfu Zhuanga,b Jinzhou Wang ${ }^{a, b}$ Junxuan Changa,b Jie Xu ${ }^{a, b}$ \\ Jianxin $Y e^{a, b}$ \\ aDepartment of Gastrointestinal Surgery 2 Section, The First Hospital Affiliated to Fujian Medical \\ University, Fuzhou, ${ }^{b}$ Key Laboratory of Ministry of Education for Gastrointestinal Cancer, Fujian Medical \\ University, Fuzhou, China
}

\section{Key Words}

Colorectal cancer - Lipopolysaccharide(LPS) - VEGFR-3 - NF-kB - Promoter - Migration • Invasion

\begin{abstract}
Background and Aim: Lipopolysaccharide(LPS) could promote the progression of colorectal cancer, but the specific regulatory mechanisms are largely unknown. So, this study aim to clarify the mechanisms that LPS upregulated VEGFR-3, which promotes colorectal cancer cells migration and invasion with a mechanism of increased NF- $\mathrm{kB}$ bind to the promoter of VEGFR-3. Methods: The present study examined the VEGFR-3 expression in colorectal cancer tissues and analyzed the relationship between the VEGFR-3 expression with clinical parameters. PCR, Western blot, CCK-8, colone formation assay, and Transwell assay detected that LPS promoted the migration and invasion and the role of VEGFR-3 in the process of colorectal carcinoma in vitro. Used the methods of promoter analysis, EMSA assay and ChIP assay to explore the mechanisms LPS increased the expression of VEGFR-3. Results: VEGFR-3 was significantly high expression in the colorectal cancer tissues. And the high expression was associated with the TNM stage and lymph node metastasis of colorectal cancer. LPS could promote the migration and invasion, which could be blocked by the neutralizing antibody IgG of VEGFR-3. And found that -159 nt to +65 nt was the crucial region of VEGFR-3 promoter. And detected that the NF-KB was important transcription factor for the VEGFR-3 promoter. And LPS could increase NF- $\mathrm{KB}$ binding to VEGFR-3 promoter and upregulated the expression of VEGFR-3 to exert biological functions. Conclusion: We have elucidated the relationship between LPS and the VEGFR-3 expression and revealed that VEGFR-3 play very important role in the process of LPS promoting the migration and invasion of colorectal cancer cells. Further




\section{Cellular Physiology Cell Physiol Biochem 2016;39:1665-1678 \\ \begin{tabular}{ll|l} 
and Biochemistry & $\begin{array}{l}\text { DOI: 10.1159/000447868 } \\
\text { Published online: September 19, } 2016\end{array}$ & $\begin{array}{l}\text { (c) 2016 The Author(s). Published by S. Karger AG, Basel } \\
\text { www.karger.com/cpb }\end{array}$ \\
\hline
\end{tabular} \\ Zhu et al.: LPS Increased VEGFR-3 Promoting the Migration and Invasion of Colorectal Cancer}

illuminated the mechanism that LPS upregulated VEGFR-3 expression via increased NF-KB bind to the promoter of VEGFR-3.

\section{Introduction}

Colorectal cancer is the fourth most common cancer and the second cause of cancerrelated deaths in USA. And, in China colorectal cancer also has been ranked as the fourth most common malignancies among women and the fifth among men [1-3]. Up to now, radical resection of the colorectal cancer still is the best choice for the treatment. Despite lymph node negative status, $10-30 \%$ of patients with colorectal cancer develop local recurrence or distant metastasis within five years after curative resection [4]. The basis for recurrence and metastasis of colorectal cancer is poorly understood.

The relationship between inflammation and carcinoma is an ancient issue. Rodolf Virchow [5] first addressed the hypothesis that inflammation and cancer coexisted. And some studies has proved that inflammation promotes the progression of cancer [6, 7]. And there are mounting evidences linking inflammation or infection which can induce inflammation to recrrence of colorectal cancer [8,9]. Infection can trigger a cascade of inflammatory response mediated by various inflammation cell types and the infalmmatory can promote the cancer progression. However, the mechanisms of infection promote cancer progression still keep largely unclear.

Lipopolysaccharide(LPS), a gram-negative bacterial antigen involved in the progression of colorectal cancer [10], can cause significant systemic locational inflammation of colorectal and systemic inflammation of organism. However, the specific mechanism by which LPS promotes the progression of colorectal carcinoma has not been absolutely elucidated. Lots of studies have shown that LPS participate in and promote a wide variety of tumor progression and metastasis. Liu et al. [11] found that LPS could stimulate the secretion of IL-8 and TGF- $\beta 1$ to promote the proliferation and invasion of liver cancer cells. Huang et al. [12]reported that LPS induced the expression of MMPs increased the invasiveness of leukemia cells. And some studies also found that LPS could promote the epithelial-mesenchymal transition of tumor cells to enhance the cancer cells invasiveness $[13,14]$. However, LPS promote the specific mechanisms of progression of carcinoma is not entirely clear.

We tested the LPS concentration of the tissues of colorectal cancer and para-carcinoma found that the LPS concentration were significantly increased in the colorectal cancer tissues. And futher study found that LPS concentration has relationship with the lymph node metastasis in colorectal cancer.

VEGFR-3 is a receptor tyrosine kinase that is expressed in lymphatic endothelial cells [15]. And VEGFR-3 high expression result in lymph node metastasis and decreased survival [16]. Several tumor types found that VEGFR-3 were high expression $[17,18]$. So, in this article, we report that LPS upregulste VEGFR-3, which promotes colorectal cancer cells migration and invasion with a mechanism of increased NF- $\kappa B$ bind to the promoter of VEGFR-3.

\section{Materials and Methods}

\section{Patients tissues and data collection}

This study of human colorectal cancer sample was approved by the Ethics Committee of the First Hospital Affiliated to Fujian Medical University. Human colorectal cancer samples and their paired adjacent normal colorectal mucosa tissues were collected from the First Affiliated Hospital of Fujian Medical University (Fuzhou, China) in 2015. Samples were immediately stored in liquid nitrogen after surgical resection. All the patients in our study did not received preoperative chemotherapy, radiotherapy, or biological treatment. We got all the patients' written informed consent of the samples. 


\section{Cellular Physiology Cell Physiol Biochem 2016;39:1665-1678 \begin{tabular}{l|l|l} 
and Biochemistry $10.1159 / 000447868$ & (c) 2016 The Author(s). Published by S. Karger AG, Basel \\
www.karger.com/cpb
\end{tabular} Zhu et al.: LPS Increased VEGFR-3 Promoting the Migration and Invasion of Colorectal Cancer}

Immunohistochemistry and evalution

Immunohistochemistry was performed as described before [19]. Rabbit polyclonal anti-human VEGFR-3 antibody(1:300)(from Abcam biotechnologoy) was used in the experiment. The diagnoses were confirmed and the stained sections were evaluated independently by two experimenters who were trained about the patological diagnosis suing a conventional light microscope. The percentage of positive cells within the entire rate of epithelial cells were assessed and assigned to one of the following principle: negative $\leq 25 \%, 25 \% \leq$ positivity $\leq 75 \%$. The intensity of immoreactivity was also evaluated for being negative and positivity for every case.

\section{Cell lines and materials}

The two colorectal cancer cell lines (sw480, HCT116) were obtained from cell bank of the Chinese Academy of Sciences (Shanghai, China). Both cell lines were cultured in RPMI 1640 with L-glutamine supplemented with 10\% fetal bovine serum in 5\% CO2. Lipopoly-saccharide (Escherichiacoli 055:B5) was obtained from Sigma-Aldrich (St Louis,MO, USA). LPS was dissolved in PBS. RPMI 1640 with L-glutamine and fetal bovine serum were from GIBCO (Gaithers- burg, MD, USA). The primers for VEGFR- 3 and $\beta$-actin were as follows: VEGFR-3 forward 5'-GAGTTTGTGGAGGGAAAGAATA-3' and reverse 5'-CCTCGGATGGCTTGGATT-3'; $\beta$-actin forward 5'-CTGTCT GGCGGCACCACCAT-3' and reverse 5'-GCAACTAAGTCATAGTCC GC-3'.

\section{RNA preparation, reverse transcription, and real-time PCR amplification}

Semiquantitative RT-PCR was used to detect the expression of VEGFR-3 gene in colorectal cancer cell lines SW480 and Hct116 respectively. And the RNA preparation, reverse transcription and qPCR amplification and the analysis results were carried out as described previously [19].

\section{Western-blot analysis}

Western blot and detection of the blotted product were carried out as described previously [20]. The following primary antibodies were used from the different companies under listing respectively: Rabbit polyclonal anti-human VEGFR-3 antibody (1:1000)( from Abcam biotechnologoy), nuclear factor- $\mathrm{B}$ (NF$\kappa B)(p 65)$ monoclonal mouse anti-human antibody(1:500), p-NF- $\kappa B$ (p-p65) monoclonal mouse anti-human antibody (1:500) (both from Cell Signaling Technology, Danvers, MA, USA), $\beta$-actin monoclonal mouse antihuman antibody (1:1500) (from Santa Cruz Biotechnology, Inc.Santa Cruz, CA, USA). Primary antibodies behind Figures in brackets stand for the antibody dilution multiple.

\section{Cell proliferation assay, cell migration and invasion assay}

Cells were seeded onto 96-well plates at a density of 1,500 cells per well and detected using the cell counting kit CCK-8 (Donjindo, Kumamoto, Japan) by a microplate reader (Bio-Tek, Winooski, VT, USA) for 5 days. The data of absorbance at a wavelength of $450 \mathrm{~nm}$ was collected to analyze cell proliferation. Tranwell chamber ( $8 \mu \mathrm{m}, 24$-well format;FALCON) and Matrigel coated transwell chamber (BD Bioscience) were inserted into 24 well cell cuture plates to measure migration and invasion. $9 \times 10^{4}$ cells in $0.3 \mathrm{~mL}$ of serumfree medium were added in the upper chamber, while $0.8 \mathrm{~mL}$ of RPMI 1640 containing 10\% FBS was added to the lower chamber. Cells were cultured for 24 hours. Then cells with transwell chambers were fixed in methanol for 5 minutes and stained with crystal violet and counted in 3 random fields under microscope. LPS was dissolved in culture medium at required concentration and used for the intervention experiment.

\section{Plasmid constructs}

We extracted genomic DNA from sw480 cells to use Dneasy Tissue Kit(Qiagen, Hilden, Germany), which was used as a template for polymerase chain reactin(PCR) amplification. The plasmid pGL3B-1659 was constructed by ligation of the PCR-produced longest VEGFR-3 promoter (nucleotides -1659 to +65 , relative to the transcription start site), and the longest fragment were containing HindIII and XhoI restriction site, which was connected to the pGL3-Basic vector(Promega). Kinds of VEGFR-3 promoter plasmid were constructed, which included, pGL3B-1159, pGL3B-834, pGL3B-609, pGL3B-334, pGL3B-159 and pGL3B-59. and these plasmids were constructed the same as pGL3B-1659. The pGL3B-159 plasmid was used as a template for the construction of NF- $\mathrm{B}$-binding sites mutants. We constructed the mutant plasmids using the overlap PCR technology. And the mutant plasmids were named pGL3B-159-mut. To obtain overexpression plasmids pcDNA3.0-NF- $\mathrm{B}$ (p65), PCR was carried out with a superscrit library (Life Technologies) using 
Cancer

the template human full-length cDNA sequence of NF- $\kappa \mathrm{B}$ (p65) and the PCR-generated NF$\kappa \mathrm{B}(\mathrm{p} 65)$ gene was insersted into the XhoI-HindIII site of pcDNA3.0 (Promega, Madison, WI). All above constructs were confirmed by DNA sequencing. The primers of PCR amplification are shown in Table 1.

Transfection and dual-luciferase reporter assay

Cells were plated at density of $2 \times 10^{5}$ cells/well. DNA transfection was carried out in 12 -well plates by use of Lipofectamine 3000 (Life Technologies), in according with the manufacturer' 3 recommendations. The small interfering RNA (siRNA) targets for NF- $\kappa \mathrm{B}$ (5'-CUCAAGAUCUGCCGAGUGA-3') were synthesized (Beyotime, shanghai, China); 100 pmol of siRNA- NF- $\kappa$ B was used for transfection. mRNA and proteins were extracted at $48 \mathrm{~h}$ after transfection. Cells with different treatment were transfected with VEGFR-3 promoter vetors. A later of $48 \mathrm{~h}$ after transfection, cells were lysed. A total of $20 \mathrm{ug}$ of cell lysate was used for the detection of intracellular luciferase activity following the manufacturers' recommendations. The renilla luciferase expression vector pRL-TK (promega) was used for normalization, and the promoterless vector pGL3-Basic served as the negative control. Luminescence measurement was performed on a luminometer (Orion II Microplate Luminometer, Berthold Detection Systems, Germany). Each transferction was performed in duplicate and data were expressed as the mean \pm SD of three separate experiments.

Identification of putative transcription factor binding sites

A computer-based search for potential transcription factor binding site motifs was carried out on the TESS(http://www.cbil.upenn.edu/cgi-bin/tess/tess) [21], TFBIND (http://tfbind.hgc.jp/) [22] and TFSEARCH (http://ww w.cbrc.jp/research/db/TFSEARCH.html) [23].

\section{Nuclear extration and electrophoretic mobility shift assay(EMSA)}

The 5'-biotin end-labeled oligonucleotides that corresponded to the NF- $\kappa \mathrm{B}$ transcription factor recognition sequences within the VEGFR-3 promoter region were synthesized by beyotime Institute of Biotechnology and used as probes.Unlabeled oligonucleotides, either wild type that we called the cold probes or mutated which indicated mutated cold probes including the NF- $\kappa$ B mutation sites were used as competitors. Oligonucleotides sequences are shown in Table 1. Double-stranded oligonucleotides were obtained by annealing equal amounts of the complementary single-gradually cooling to room temperature. The nuclear proteins from $10^{7}$ cells were prepared by Nuclear Extraction Kit (Beyotime) following the manufacturer's instructions. An EMSA Gel Shift Kit (Affymetrix, Santa Clara, CA) was used to examine the interaction between NF- $\mathrm{KB}$ in the nuclear extract with the probe, in accordance with the manufacturer's instructions. In briefly, 7 ug of nuclear proteins were incubated with $1 \mathrm{ug}$ of $\mathrm{dI}$-dC and 0.02 pmol labeled probe in a final $10 \mathrm{ul}$ reaction system. The competition assay was carried out using 100 fold molar excess of cold probes of cold mutated probes, pre-incubated with the reaction mixture before addition of biotinlabeled probes. The DNA-protein complexes were incubated at room temperature for $30 \mathrm{~min}$, and then had electrophoresis on a $6 \%$ non-denaturing pre-made polyacrylamide gel. And then the complexes were transferred to a nylon membrance and fixed for 10 min using a UV lights. The biotin end-labeled DNA was detected by addition of a streptavidin-horseradish peroxidase conjugate and a chemiluminescent substrate. 


\section{Cellular Physiology Cell Physiol Biochem 2016;39:1665-1678 \\ \begin{tabular}{l|l|l} 
and Biochemistry Published online: September 19, 2016 & $\begin{array}{l}\text { (c) } 2016 \text { The Author(s). Published by S. Karger AG, Basel } \\
\text { www.karger.com/cpb }\end{array}$
\end{tabular} \\ Zhu et al.: LPS Increased VEGFR-3 Promoting the Migration and Invasion of Colorectal Cancer}

\section{Chromatin immunoprecipitation assay (ChIP)}

Total of $10^{7}$ colorectal cancer cells were cultured and crosslinked by adding formaldehyde to a final concentration of $1 \%$ at room temperature for $10 \mathrm{~min}$. The cross-linking was stopped by adding of 125 $\mathrm{mM}$ glycine at room temperature for $5 \mathrm{~min}$. Cells were rinsed twice and collected with ice-cold phosphatebuffered saline (PBS). Then cells were resuspended in $0.75 \mathrm{ml}$ FA lysis buffer (Abcam, Cambridge, MA) and incubated on ice for $15 \mathrm{~min}$. Cell lysates were sonicated for $20 \mathrm{~min}$. Immunoprecipitation was conducted with $5 \mathrm{mg}$ of antibodies (anti- NF- $\mathrm{BB}$ ) followed by $80 \mathrm{ul}$ of pre-blocked protein A/G. following elution and proteinase $\mathrm{K}$ digestion, DNA was recovered by phenol/chloroform extration and ethanol precipitation in the presence of glycogen and dissolved in $100 \mathrm{ul}$ distilled sterile water. Bound target DNA fractions were amplified by PCR. The primers used for are as follows: forword, 5'-GCGCACTGCTCGGGT-3' and reverse, 5'-GCGGCTCGGGGCTGAAAG-3'.

\section{Statistical analysis}

All statistical analysis used GraphPad Prism 5 software. Data were analyzed by the variance (ANOVA) or Student's t-test. The data were expressed as the means \pm standard deviation(SD). A P-value $<0.05$ was considered to indicate a statistically significant difference.

\section{Results}

The VEGFR-3 gene expression in human colorectal cancer by immounohistochemistry staining

We analyzed the expression of VEGFR-3 in 30 clinical samples from colorectal cancer patients and 30 paired of normal colorectal tissues located away from the cancer site using immunohistochemistry technology. In the para-carcinoma tissues, the expresssion of VEGFR-3 were negative or low in the normal colorectal mucosa cells (Fig. 1A); however, the in the colorectal cancer tissues the expression of VEGFR-3 were positive or high (Fig. 1B). And the difference has significant meaning $(\mathrm{P}<0.05)$ (Table 2$)$. So, the positive or overexpression of VEGFR-3 may promote progression of colorectal cancer.

Table 3 indicates the relationship between VEGFR-3 expression and clinicopathologic parameters. There was a significantly relationship between VEGFR-3 positive-expression and clinical stage (I II vs. III IV; P=0.0318<0.05), T stage(T1 T2 vs. T3 T4; P=0.0256<0.05), and lymph node metastasis (Negative vs. Positive; $P=0.0004<0.05$ ). VEGFR-3 expression did not vary markedly with age, gender, tumor size, $M$ stage and histologic grade.

\section{LPS increased the VEGFR-3 exprssion in vitro}

We analyzed the mRNA and protein expression of VEGFR-3 in the sw480 and HCT116 cells. Using qPCR and western-blot we detected the mRNA and protein of VEGFR-3 in both cell lines.The mRNA and protein expression levels were similar between the sw480 and HCT116 cells (Fig. 2A and B). So, we used the both cell lines to test the biology role for our experiments.

We tested the expression of VEGFR-3 in the sw480 and HCT116 cells after treatment with exogenous LPS to determine whethwe LPS could increased the expression of VEGFR-3.

Fig. 1. Different expression of VEGFR-3 in human colorectal tissues. (A) Negative or mild expression of VEGFR-3 in normal colorectal samples located away from cancer (400x) (B). Positive or strong expression of VEGFR-3 in tumor cells of colorectal cancer $(400 \times)$.

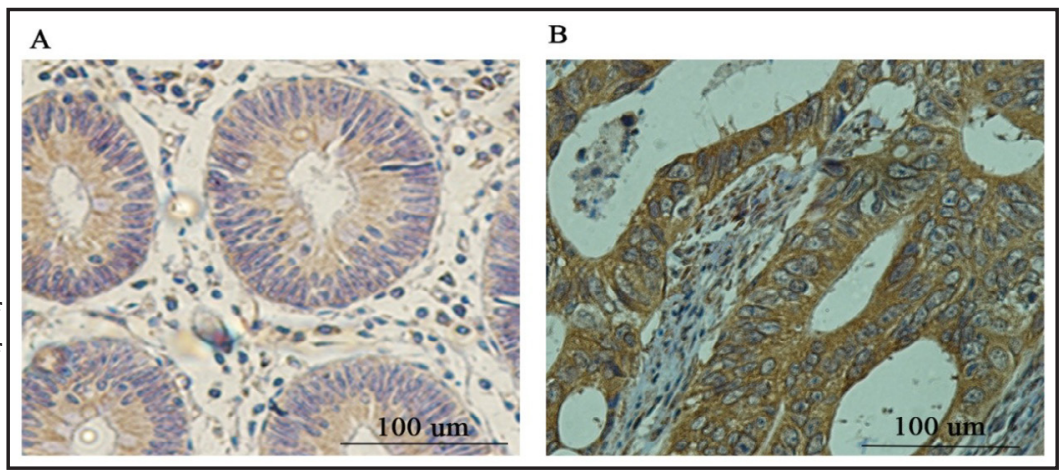




\section{Cellular Physiology Cell Physiol Biochem 2016;39:1665-1678 \\ \begin{tabular}{l|l|l} 
and Biochemistry & Published online: September 19, 2016 & $\begin{array}{l}\text { (c) 2016 The Author(s). Published by S. Karger AG, Basel } \\
\text { www.karger.com/cpb }\end{array}$ \\
\hline
\end{tabular} \\ Zhu et al.: LPS Increased VEGFR-3 Promoting the Migration and Invasion of Colorectal Cancer}

Sw480 and HCT116 cells were seeded into 6-well plates and treated with different doses of LPS $(0 \mathrm{ng} / \mathrm{ml}, 200 \mathrm{ng} / \mathrm{ml}, 500 \mathrm{ng} / \mathrm{ml}$, and $800 \mathrm{ng} / \mathrm{ml}$ ) for $24 \mathrm{~h}$. The relative mRNA and protein of VEGFR-3 were detected by real-time PCR and western-blot methods. As shown in Fig. 2 and F, LPS promoted the transcription and protein expression of VEGFR-3 in sw480 (Fig. 2C and D) and HCT116 (Fig. 2E and F) cells in a dosedependent manner.

VEGFR-3 owned very important roles in the process of LPS promoting migration and invasion of SW 480 and HCT116 cells

We used the CCK- 8 assay to detected the ability of proliferation after LPS treatment in sw480 and HCT116 cells. We used the different LPS concentrations $(0 \mathrm{ng} / \mathrm{ml}$ and $800 \mathrm{ng} / \mathrm{ml}$ ) to stimulate sw480 and HCT116 cells. And then we examined cell proliferation at 1, 2, 3, 4 and 5 days. The results shown that $800 \mathrm{ng} / \mathrm{ml}$ LPS could not promote the cell proliferation compared to $0 \mathrm{ng} / \mathrm{ml}$ LPS for the sw480 and HCT116 cells (Fig. 3A and B). For verification our results, we carried out colorectale formation assay and got the same conclusion as CCK-8 assay that there were not different between LPS-800 $\mathrm{ng} / \mathrm{ml}$ and LPS-free group in the sw480 and HCT116 at the aspect of cell proliferation (Fig. 3C and D).

To determine wether the migration and invasiveness of sw480 and HCT116 after LPS stimulation, we used Transwell assay to examine the effects of LPS. The results shown that the LPS-800 ng group total numbers of migrated and invaded cells through the Transwell polycarbonate filter was significantly higher than the LPS-free group in both
Table 2. The VEGFR-3 expression situation in the colorectal cancer tissues and normal colorectal tissues. $* \mathrm{P}<0.05$

\begin{tabular}{lcccc}
\hline \multirow{2}{*}{ Groups } & \multicolumn{4}{c}{ VEGFR-3 expression } \\
Colorectal tissues & 30 & 8 & 22 & \\
Normal colorectal tissues & 30 & 20 & 10 & $0.004^{*}$ \\
\hline
\end{tabular}

Table 3. Correlation between clinicopathological factors and VEGFR-3 expression in colorectal cancer. Note: ${ }^{\text {a }}$ the $7^{\text {th }}$ edition of TNM staging criteria of colorectal cancer. ${ }^{*} \mathrm{P}<0.05$

\begin{tabular}{|c|c|c|c|}
\hline \multirow[b]{2}{*}{ Factors } & \multicolumn{2}{|c|}{ VEGFR-3 expression } & \multirow[t]{2}{*}{$P$} \\
\hline & Negative & Positive & \\
\hline \multicolumn{4}{|l|}{ Age(year) } \\
\hline$<60$ & 5 & 8 & \multirow[t]{2}{*}{0.242} \\
\hline$\geq 60$ & 3 & 14 & \\
\hline \multicolumn{4}{|l|}{ Gender } \\
\hline Male & 4 & 15 & \multirow[t]{2}{*}{0.4172} \\
\hline Female & 4 & 7 & \\
\hline \multicolumn{4}{|l|}{ Size $(\mathrm{cm})$} \\
\hline$\leq 3$ & 6 & 9 & \multirow[t]{2}{*}{0.2148} \\
\hline$>3$ & 2 & 13 & \\
\hline \multicolumn{4}{|c|}{ Clinical stage ${ }^{\mathrm{a}}$} \\
\hline I-II & 5 & 4 & \multirow[t]{2}{*}{$0.0318^{*}$} \\
\hline III-IV & 3 & 18 & \\
\hline \multicolumn{4}{|l|}{ T stage } \\
\hline $\mathrm{T} 1-\mathrm{T} 2$ & 5 & 5 & \multirow[t]{2}{*}{$0.0256^{*}$} \\
\hline $\mathrm{T} 3-\mathrm{T} 4$ & 2 & 18 & \\
\hline \multicolumn{4}{|l|}{ M stage } \\
\hline M0 & 8 & 16 & \multirow[t]{2}{*}{0.155} \\
\hline M1 & 0 & 6 & \\
\hline \multicolumn{4}{|c|}{ Lymph node metastasis } \\
\hline Negative & 7 & 3 & \multirow[t]{2}{*}{$0.0004^{*}$} \\
\hline Positive & 1 & 19 & \\
\hline \multicolumn{4}{|c|}{ Histological grade } \\
\hline Pooly & 4 & 10 & \multirow[t]{3}{*}{0.515} \\
\hline Moderately & 1 & 7 & \\
\hline Well & 3 & 5 & \\
\hline
\end{tabular}

cell lines. To test the roles of VEGFR-3 in the LPS increasing the migration and invasion of sw480 and HCT116 cells, we used the IgG antibody of VEGFR-3 $(10 \mathrm{ug} / \mathrm{ml})$ to block its biologic activity. As a results, the ability of migration and invasion of LPS-800 ng/ml-IgG group demonstrated a significant decrease compared to the LPS- $800 \mathrm{ng} / \mathrm{ml}$ group in the sw480 and HCT116 cells (Fig. 3E and F). Together, these results indicated that the VEGFR-3 was vital to LPS promote migration and invasion of sw480 and HCT116 cells.

The expression of TLR4 protein and LPS the roles of activated NF- $\mathrm{KB}$ in sw480 and HCT116 cells.

To detected the expression of TLR4 which is the receptor of LPS and LPS plays the biologic functions by the receptor in sw480 and HCT116 cells, we used the western-blot method and found that TLR4 expression in both cell lines. And the expression levels of TLR4 didn't significantly difference in sw480 and HCT116 cell lines (Fig. 4A).

To assess the activation situation of NF- $\mathrm{KB}$ in the LPS- $800 \mathrm{ng} / \mathrm{ml}$ cells, we used westernblot technology to analyze. The results shown that the p-NF- $\kappa \mathrm{B}$ was markedly increased in 
Zhu et al.: LPS Increased VEGFR-3 Promoting the Migration and Invasion of Colorectal Cancer

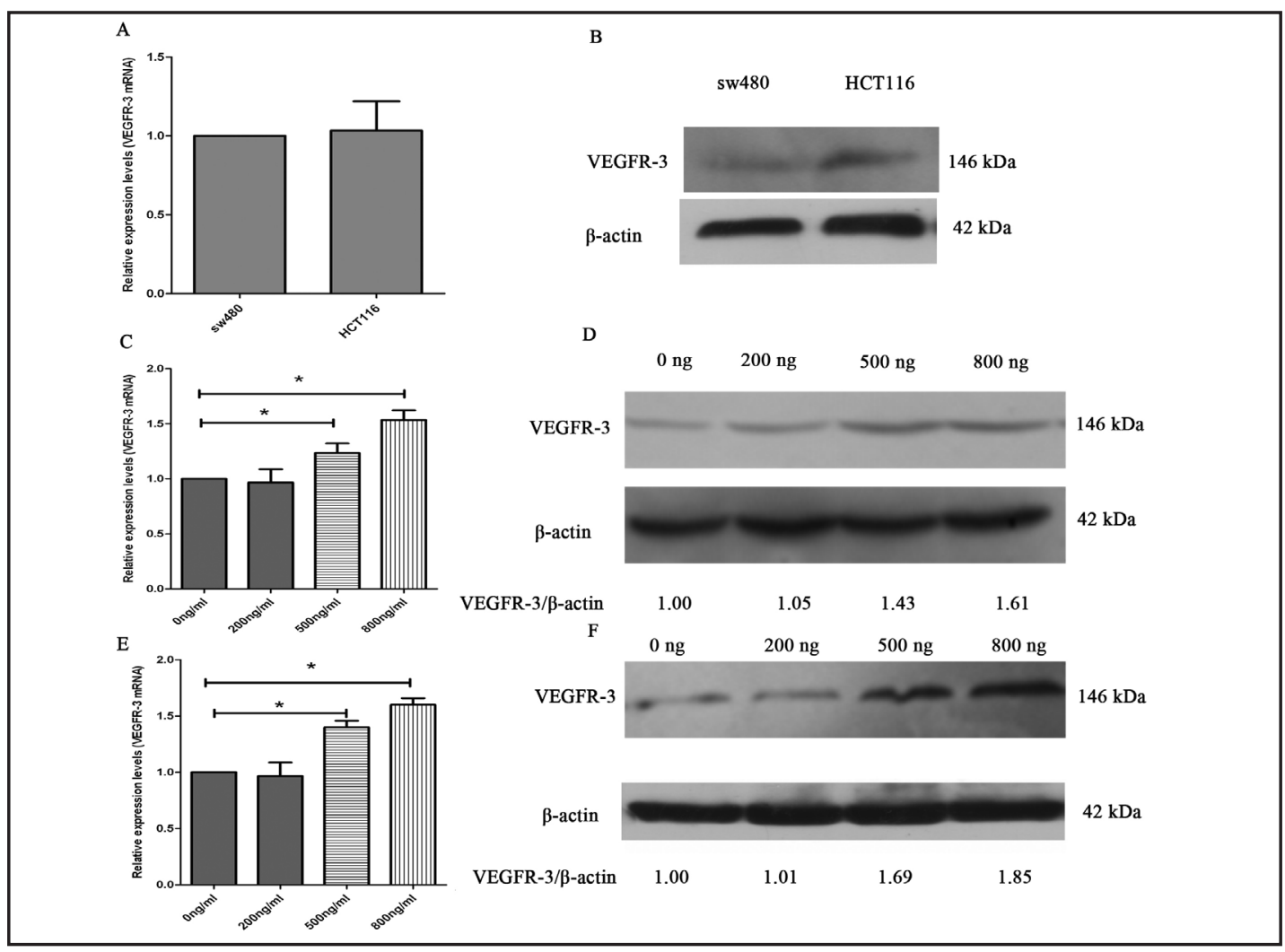

Fig. 2. LPS increased the VEGFR-3 exprssion in vitro. (A) Total RNA from human colorectal cancer cell lines sw480 and HCT116 were assessed by qPCR using VEGFR-3 primers. $\beta$-actin was amplified for an internal control. Semiquantitative analysis showed that VEGFR-3 mRNA expression levels in the w480 and HCT116 cells were not different. (B) The VEGFR-3 protein in human colorectal cancer cell lines were found by western blotting.The same as mRNA $\beta$-actin protein was used as an internal control. (C and D) LPS promote the VEGFR-3 mRNA and protein expression in sw480 cells. sw480 cells were treated with different concentration LPS $(0 \mathrm{ng} / \mathrm{ml}, 200 \mathrm{ng} / \mathrm{ml}, 500 \mathrm{ng} / \mathrm{ml}$, and $800 \mathrm{ng} / \mathrm{ml})$ for $24 \mathrm{~h}$, and qPCR and western blot detected the VEGFR-3 mRNA and protein and the relative mRNA and protein level were obtained by comparison with the LPS concentration of $0 \mathrm{ng} / \mathrm{ml}$, which was set to 1 . LPS- $800 \mathrm{ng} / \mathrm{ml}$ the expression level of VEGFR-3 protein increased to 1.61 compared with LPS-free. ( $E$ and F) Representative VEGFR-3 mRNA and protein expression levels in HCT116 cells treated with different concentration LPS $(0 \mathrm{ng} / \mathrm{ml}, 200 \mathrm{ng} / \mathrm{ml}, 500 \mathrm{ng} / \mathrm{ml}$, and 800 $\mathrm{ng} / \mathrm{ml}$ ) for $24 \mathrm{~h}$. And the same as sw480 cells, VEGFR-3 mRNA and protein expression levels were highest when treated with LPS-800ng/ml. (C-F) We used the housekeeping gene $\beta$-actin as internal control. ${ }^{*} \mathrm{P}<0.05$.

sw480 and HCT116 cells of LPS-800 ng/ml group (Fig. 4B). This suggested that LPS activated NF- $\kappa B$ by TLR4.

\section{Nucleotides regions of -159 nt to +65 nt are crucial for the fully activity of the VEGFR-3} promoter

A series of 5'-deletion constructs of the VEGFR-3 gene promoter were transfected into the human colorectal cell line HCT116. As a results in Fig. 5A cells transfected by pGL3B-1659, pGL3B-1159, pGL3B-834, pGL3B-609, pGL3B-334, and pGL3B-159 plasmids shown higher relative luciferase activities than pGL3B-59 and pGL3-Basic plasmids in sw480 cells. Thus, the plasmid pGL3B-159 owned the high luciferase activity relative to the pGL3B-1659 plasmid, which indicated that the short region than included region -159 to +65 was vital for the full activity of VEGFR-3 promoter. The plasmid pGL3B-159 was selected for our studies in colorectal cell line sw480. We found that luciferase activities in cells transfected with 
Zhu et al.: LPS Increased VEGFR-3 Promoting the Migration and Invasion of Colorectal Cancer

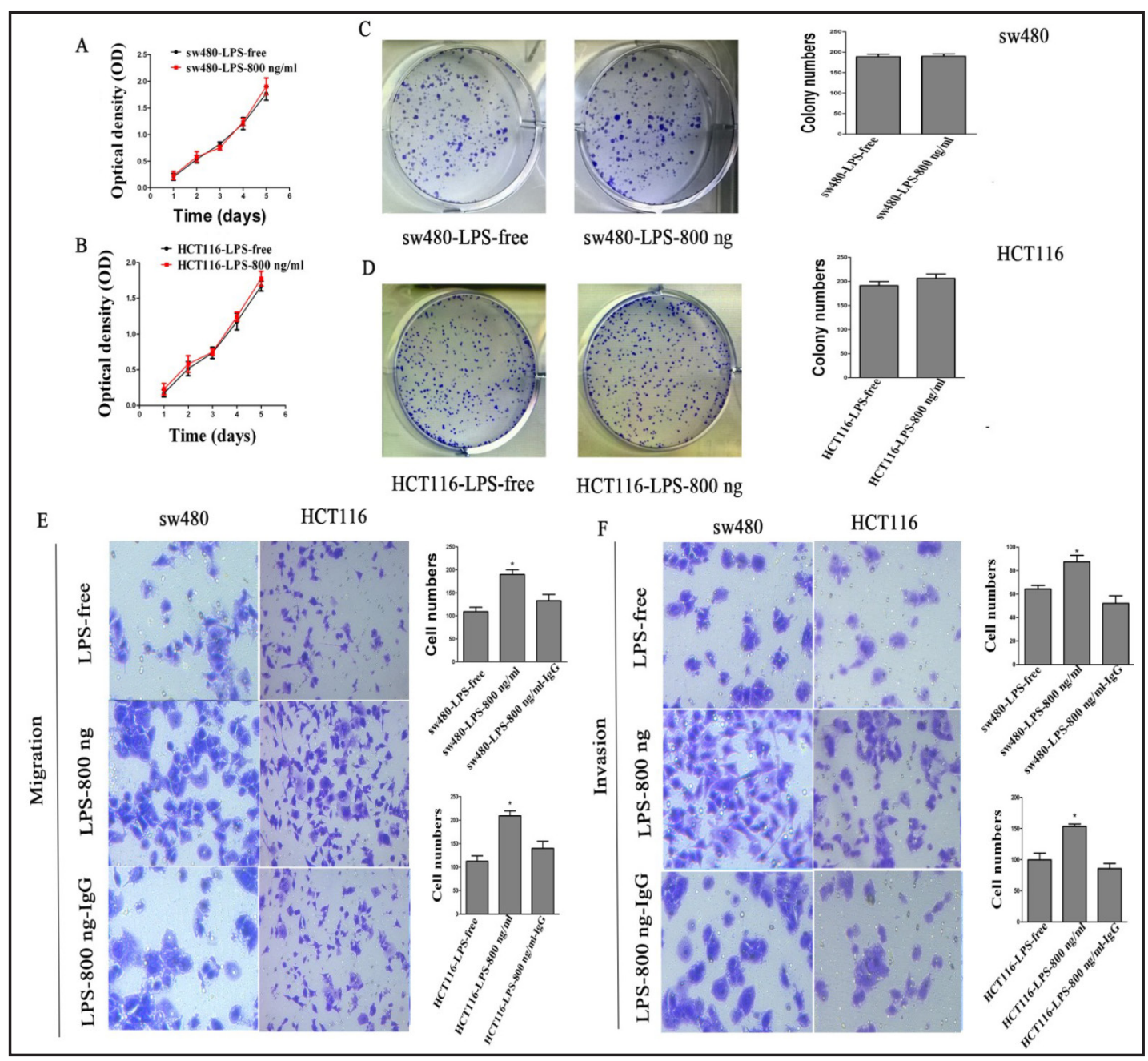

Fig. 3. VEGFR-3 owned very important roles in the process of LPS promoting migration and invasion of sw480 and HCT116 cells. (A and B) LPS $0 \mathrm{ng} / \mathrm{ml}$ and $800 \mathrm{ng} / \mathrm{ml}$ treated with sw480 and HCT116 cells. These cells proliferation hadn't difference LPS $0 \mathrm{ng} / \mathrm{ml}$ group compared with LPS-800 ng/ml group in both cell lines. (C and D) representative colone formation assays from two different cell lines treated with $0 \mathrm{ng} /$ $\mathrm{ml}$ and $800 \mathrm{ng} / \mathrm{ml}$ LPS in sw480 and HCT116 cells. The data shown that the proliferation situation LPS-800 $\mathrm{ng} / \mathrm{ml}$ group hadnot difference compared with LPS $0 \mathrm{ng} / \mathrm{ml}$ group. (E) Effect of LPS on sw480 and HCT116 celluar migration. LPS- $800 \mathrm{ng} / \mathrm{ml}$ increased the ability of migration both cell lines compared with LPS $0 \mathrm{ng} /$ $\mathrm{ml}$. The assay was assessed by transwell experiments. LPS increasing sw480 and HCT116 cells migration ablity could be blocked by IgG which could block the activity of VEGFR-3. Shown are quantitative evaluation of the results(right panel). (F) Effect of LPS on sw480 and HCT116 celluar Invasion. LPS- $800 \mathrm{ng} / \mathrm{ml}$ increased the ability of invasion both cell lines compared with LPS $0 \mathrm{ng} / \mathrm{ml}$. The assay was assessed by transwell experiments. LPS increasing sw480 and HCT116 cells invasion ablity could be blocked by IgG which could block the activity of VEGFR-3. Shown are quantitative evaluation of the results(right panel). ${ }^{*} \mathrm{P}<0.05$.

pGL3B-59 plasmid were much lower than the luciferase activities of pGL3B-159 plasmid, which shown an vital role for the region -159 nt to -59 nt in VEGFR-3 promoter regulation. Several bioinformatics softwares were used to search for probable transcription factor binding sites in the region. NF- $\kappa B$ site was detected to be situated in the region - $137 \mathrm{nt}$ to -128 nt (Fig. 5B). We used the method of verlap PCR to mutate NF- $\kappa B$ binding site and constructed $\mathrm{NF}-\kappa \mathrm{B}$ mutation plsmid, then measured the mutation plasmid relative luciferase activities. As shown in Fig. $5 \mathrm{C}$ mutation NF- $\kappa \mathrm{B}$ binding site led to a reduction in the promoter activity of about $40 \%$ as compared with the control non-mutated construct (pGL3B-159). Which 


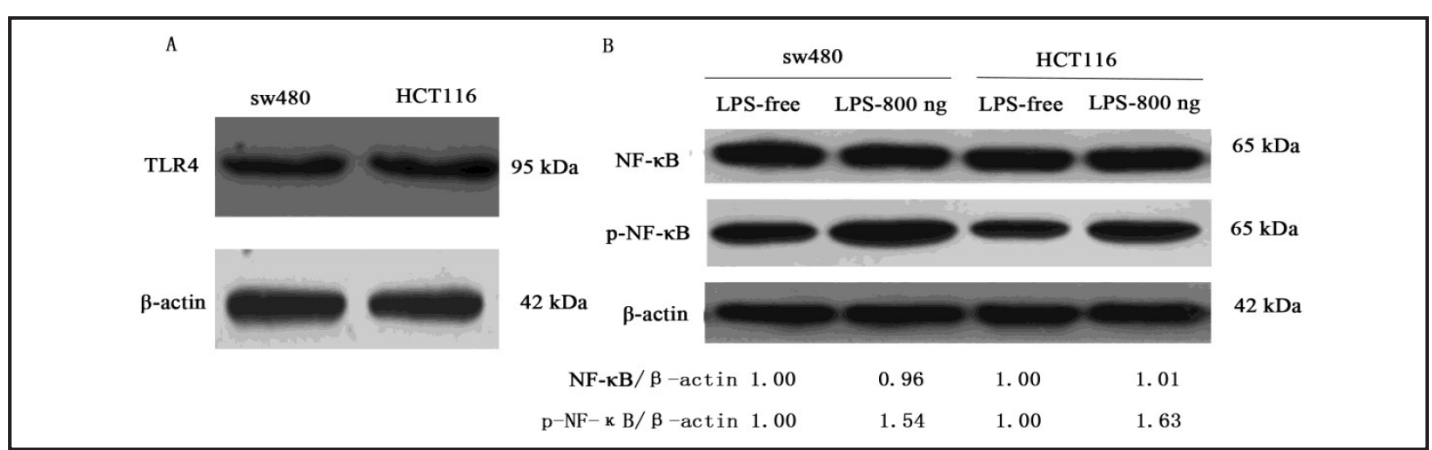

Fig. 4. Western blot analysis suggested that the TLR4 expression and LPS promoted the expression of p-NFкB in the sw480 and HCT116 cells. $\beta$-actin protein expression was used as an internal control. The densitometric value for all groups were normalized to the internal control and relative expression levels with the following equation: normalization of all groups / the first normalized value. The LPS concentration of $0 \mathrm{ng} / \mathrm{ml}$ group was set to 1 . LPS-800 $\mathrm{ng} / \mathrm{ml}$ the expression level of p-NF- $\mathrm{KB}$ protein increased to $1.54 / 1.63$ compared with LPS-free, respectively, in sw480 and HCT116 cells. However, the NF- $\mathrm{kB}$ expression level had no markedly difference.

suggested that NF- $\kappa B$-binding site are very important for the activity of pGL3B-159 plasmid.

\section{LPS promotes NF- $\kappa B$ binding to the VEGFR-3 promoter}

Upon treatment with LPS, the activity of pGL3B-159 plasmid increased markedly $(\mathrm{P}<0.05)$ and the activity of pGL3B-159 plasmid shown the LPS concentration dependence (Fig. 5D and E).

To confirm the role of NF- $\mathrm{B}$ in the VEGFR-3 promoter activity, we constructed overexpression plasmid of PcDNA3.0-NF- $\kappa B$ and siRNA- NF- $\kappa$ B. The results shown that overexpression NF- $\kappa B$ significantly increased the relative luciferase activity of pGL3B-159 plasmids and the pGL3B-159 plasmid relative luciferase activity increasing depended on the PcDNA3.0-NF- $\mathrm{KB}$ concentration (Fig. 6A, B and E), but not the pGL3B-159-mut plasmid (Fig. 6F). Another, siRNA-NF- $\kappa B$ knockdown the endogenic NF- $\kappa B$ expression observably decreased the pGL3B-159 plasmids relative luciferase activity (Fig. 6C and D).

The NF- $\kappa B$ binding site was further confirmed by EMSA of nuclear extracts for sw 480 cells with or without LPS treatment. As results shown in Fig. 7A. The unclear extracts were combined with biotin-labeled probe (lane 3). LPS increased the combined rates of the nuclear extract and the NF- $\mathrm{kB}$-binding site (lane 5). A competition assay shown that preincubation with a 100-fold molar excess of the cold probe (lane 2), but not the cold mutated probe diminished the intensity of bands (lane 4).

To confirme whether the NF- $\mathrm{B}$ is relationship with the VEGFR-3 promoter in vivo, we carried out ChIP assays with NF- $\mathrm{KB}$-specific antibody and PCR amplification. DNA nucleotides including the site of NF- $\mathrm{BB}$ were amplified ChIP with an anti- NF- $\kappa \mathrm{B}$ antibody. We used the input DNA as positive control and no antibody as negative control. And using normal IgG

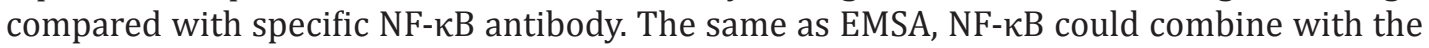
DNA seqences, which could be enhanced by LPS (Fig. 7B).

The list results demonstrate that the NF- $\mathrm{BB}$ transcription factor can combine directly with the binding sites in the VEGFR-3 promoter nucleotides and the LPS can enhance the combined effect.

\section{Discussion}

VEGFR-3 also known as Flt4, was one of the members of the famlily of tyrosine kinase receptor. VEGF-C and VEGF-D are the important ligands of VEGFR-3 and VEGF-C/VEGF-DVEGFR-3 signal axis play very important role in the process of metastasis through a paracrine or autocrine mechanisms between cancer cells and the tumor microenviroment [24, 25]. And 


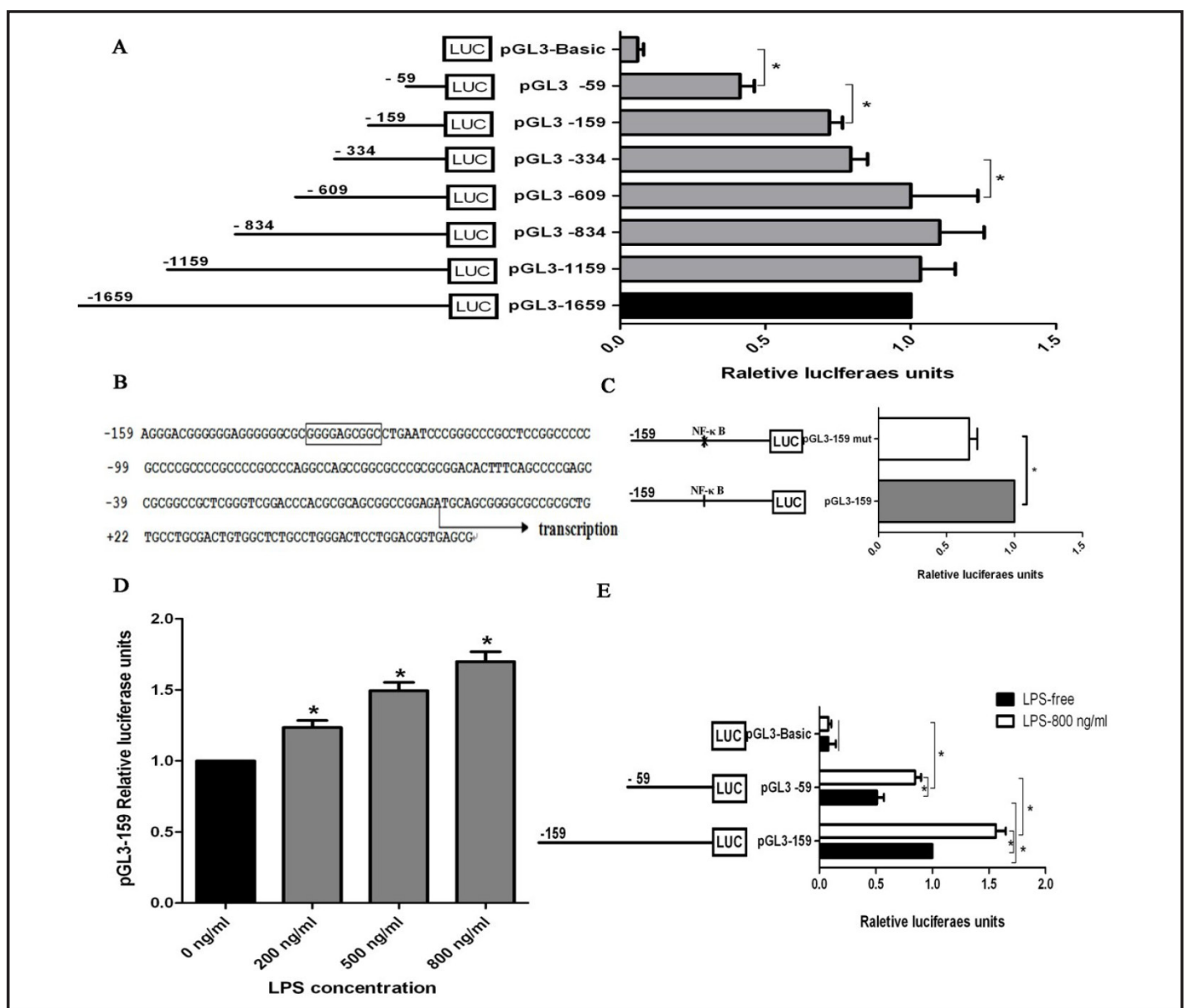

Fig. 5. Activity analysis of VEGFR-3 promoter and effects of LPS to VEGFR-3 promoter activity. (A) sw480 cells were transfected with plasmids that included different VEGFR-3 promoter fragments as follows: pGL3B-1659, pGL3B-1159, pGL3B-834, pGL3B-609, pGL3B-334, and pGL3B-159, pGL3B-59 and pGL3-Basic. And the renilla luciferase expression vector pRL-TK was used for normalization, and the promoterless vector pGL3-Basic served as the negative control. After transfection $48 \mathrm{~h}$ luciferase activities were measured. The relative luciferase units were obtained by comparison with the longest of VEGFR-3 promoter(pGL3B-1659), which was set to 1. Each transfection was carried out in duplicate and the data were expression as the mean \pm SD of three times. $\left({ }^{*} \mathrm{P}<0.05\right)$. (B) Nucleotide sequence of $-159 \mathrm{nt}$ to $+65 \mathrm{nt}$ fragment of VEGFR-3 promoter is shown on the Figure. The transcription start site is ATG and A set +1 indicating by the arrow. The NF- $\mathrm{KB}$ binding sites in the nucleotide region $-137 \mathrm{nt}$ to $-128 \mathrm{nt}$ are framed. (C) Effect of mutation of the NF- $\kappa B$ binding site on the activity of the VEGFR-3 promoter. NF- $\kappa B$ mutant plasmid was construction and depicted as pGL3B-159-mut. And the pGL3B-159-mut plasmid and pRL-TK plasmid was co-transfected into sw480 cells. pGL3-Basic vector serve as the negative control. Relative luciferase activities were tested $48 \mathrm{~h}$ after transfection. The relative luciferase units were obtained by comparison with the wild vector of pGL3B-159, which was set to 1 . Each transfection was carried out in duplicate and the data were expression as the mean $\pm \mathrm{SD}$ of three times. $\left({ }^{*} \mathrm{P}<0.05\right)$. (D) LPS enhanced VEGFR-3 promoter activities. Used the different concentration of LPS( $0 \mathrm{ng} / \mathrm{ml}, 200 \mathrm{ng} / \mathrm{ml}, 500 \mathrm{ng} / \mathrm{ml}$, and $800 \mathrm{ng} / \mathrm{ml})$ treated with sw480 cells. And pGL3B-159 and pRL-TK which was used to nornalize the transfection efficiency plasmids co-transfected these cells. After transfection $48 \mathrm{~h}$, the relative luciferase units were tests and the pGL3B-159 luciferase activity ( LPS $0 \mathrm{ng} / \mathrm{ml}$ ) was set 1 . Each transfection was carried out in duplicate and the data were expression as the mean \pm SD of three times. $\left({ }^{*} \mathrm{P}<0.05\right)$. (E) Used LPS-800 $\mathrm{ng} / \mathrm{ml}$ to treated with sw480 cells which was transfected with pGL3B-159 and pGL3B-59, and pRL-TK which was used to nornalize the transfection efficiency plasmids co-transfected these cells. After transfection $48 \mathrm{~h}$, the relative luciferase units were tests and the pGL3B-159 luciferase activity( LPS $0 \mathrm{ng} / \mathrm{ml}$ ) was set 1 . Each transfection was carried out in duplicate and the data were expression as the mean $\pm \mathrm{SD}$ of three times. $\left({ }^{*} \mathrm{P}<0.05\right)$.

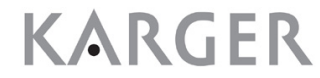


Zhu et al.: LPS Increased VEGFR-3 Promoting the Migration and Invasion of Colorectal Cancer

Fig. 6. Effects of NF-KB on VEGFR-3 promoter. (A) Western blot analysis of NF- $\mathrm{KB}$ in sw480 cells transfected with pcDNA3.0- NF- $\mathrm{BB}$ or empty vector pcDNA3.0-vector. $\beta$-actin served as a internal control. (B) Overexpression of NF-KB increased VEGFR-3 promoter activities. pcDNA3.0-NF-KB plasmid and pGL3B-159 plasmid co-transfected sw480 cells. pRL-TK plasmid was used to normalize the transfection efficiency. $48 \mathrm{~h}$ after transfection. The relative luciferase units were obtained by comprison to the pcDNA3.0-vector, which was set to 1 . Each transfection was carried out in duplicate and the data were Cells were harvested

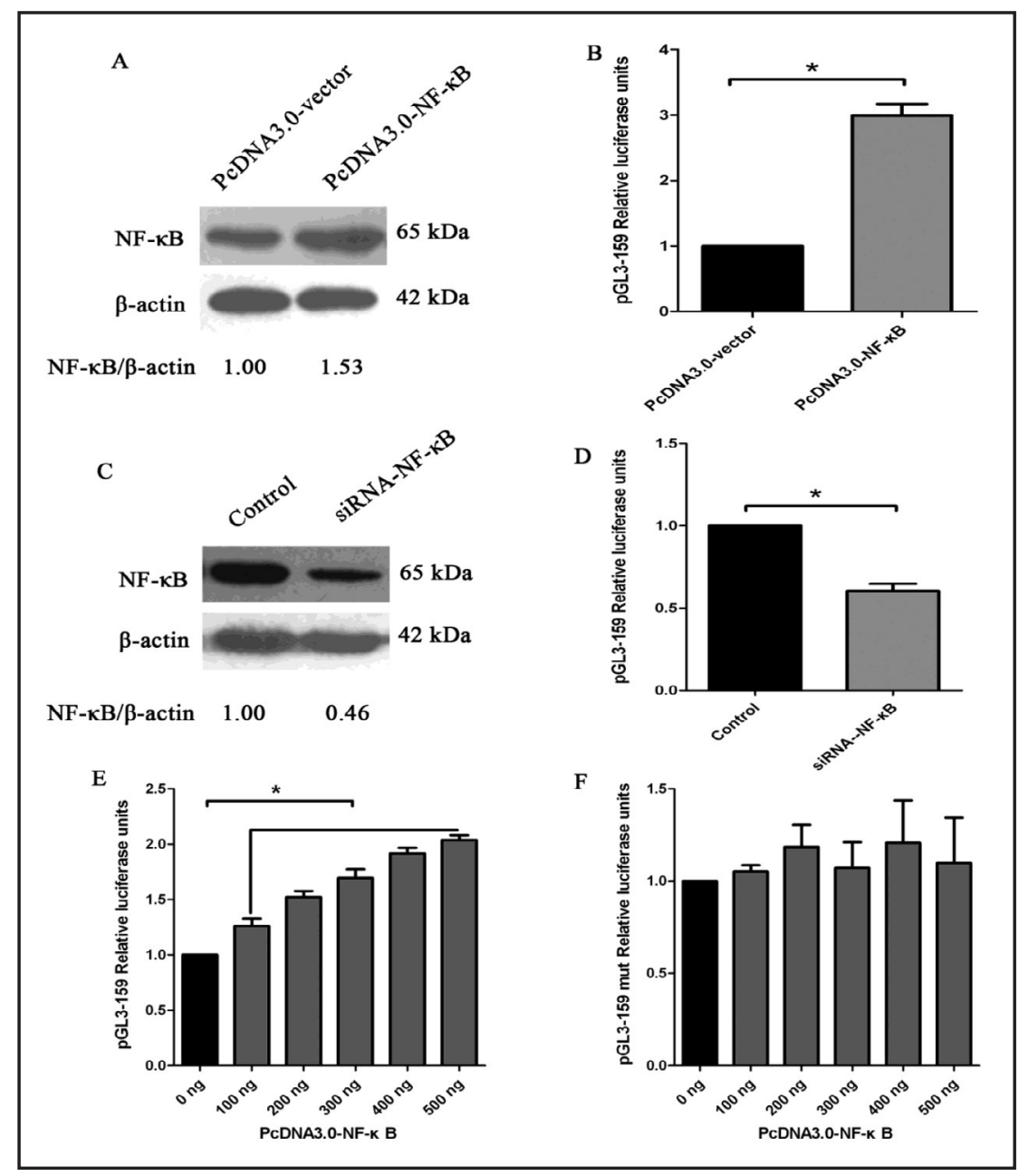
expression as the mean \pm SD of three times. $\left({ }^{*} \mathrm{P}<0.05\right)$. (C) Western blot analysis of NF-kB in sw480 cells transfected with siRNAs. sw480 cells were transfected with 100 pmol of siRNAs targets NF-KB or control. Cells were harvested $48 \mathrm{~h}$ after transfection and immunoblots were used to test NF- $\mathrm{kB}$. And $\beta$-actin served as a internal control. (D) siRNA-NF- $\mathrm{KB}$ decreased VEGFR-3 promoter activities. siRNA- NF- $\mathrm{\kappa B}$ and control RNA (control) co-transfected sw480 cells. Cells were harvested $48 \mathrm{~h}$ after transfection. The relative luciferase units were obtained by comprison to the control, which was set to 1 . Each transfection was carried out in duplicate and the data were expression as the mean \pm SD of three times. $\left({ }^{*} \mathrm{P}<0.05\right)$. (E) The VEGFR-3 promoter luciferase activity depend on the NF-אB protein concentration. sw480 cells were co-transfected with $0,200,500,800$ ng of pcDNA3.0- NF-KB, respectively. And pGL3B-159 and pRL-TK which served as internal control. pcDNA3.0- NF-kB 0 ng group was set 1 . The experiment were duplication three times . ${ }^{*} \mathrm{P}<0.05$. (F) When used the pGL3B-159-mut plasmid replacement the pGL3B-159 plasmid, we could not get the results that the luciferase activity increased depended on the dose of pcDNA3.0- NF-kB.

sever studies have reported that VEGFR-3 overexpression in cancer tissues which extracted vital role in the tumor progression [17, 18]. Rile Li et al. [26] reports VEGFR-3 expression is assosiatted with prostate cancer progression and high-level of VEGFR-3 expression increases the risk of biochemical recurrence in prostate cancer patients. In this study, we assessed the expression of VEGFR-3 in 30 clinical samples from colorectal cancer patients and 30 paired of normal colorectal tissues located away from the cancer site using immunohistochemistry technology. And the difference has significant meaning $(\mathrm{P}<0.05)$. And there was a significantly relationship between VEGFR-3 positive-expression and clinical stage, T stage, and lymph node metastasis. So, the positive or overexpression of VEGFR-3 may promote progression 
A

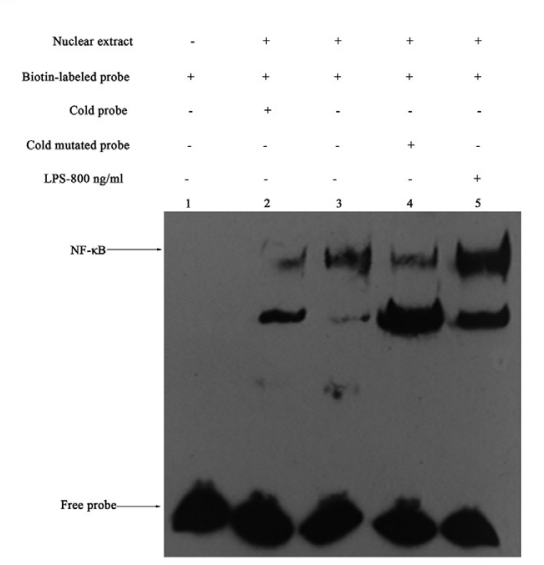

B

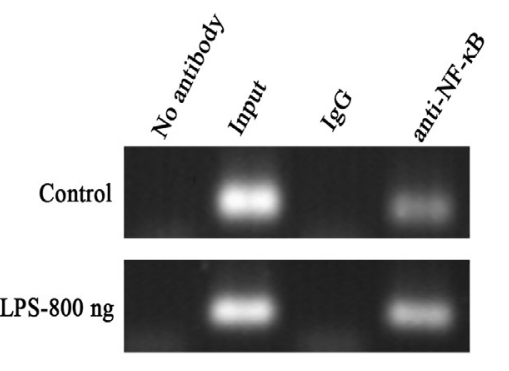

Fig. 7. Analysis of transcription factor binding site in VEGFR-3 promoter influenced by LPS. (A) EMSA of NF- $\kappa$ B. The 5-biotin end-labeled probe was incubated in the absence (lane 1) or presence (lane 3) of nuclear extracts from sw480 cells. unlabeled, cold probe( lane 2) and cold mutated probe(lane 4) were used as compertitor at a concentration of 100 fold molar excess to biotin labeled probe. The 5 -biotin end-labeled probe was incubated in the presence of nuclear extracts from sw480 cells that were treated with LPS-800 ng/ml (lane 5). (B) ChIP assay. Chromatin from sw480 cells immunoprecipitated with the anti-NF- $\kappa$ B. The total extracted DNA which set input prior to immunoprecipitation and the immunoprecipitated samples were PCR amplified using primers specific to a region that included the binding site which is specific binding site of NF- $\kappa B$ of the VEGFR-3 promoter. The normal rabbit IgG or no antibody was carried out experiments as control purpose. ChIP assay was performed for twice. As shown in the Figure that LPS enhanced the NF- $\kappa B$ binding to the VEGFR-3 promoter.

of colorectal cancer. This results were the same as previous studies about colorectal cancer [27].

In the process of our study about LPS in the colorectal cancer tissues, we found that LPS concentration were increased in the colorectal cancer tissues that VEGFR-3 expression were positive compared to the normal colorectal tissues. So, we thought that LPS could upregulate the expression of VEGFR-3 which could promote the progression of colorectal cancer. And further to analyze the underlying mechanisms of LPS increasing expression of VEGFR-3.

So, we tested the VEGFR-3 expression in sw480 and HCT116 cells. And found that LPS promoted the transcription and protein expression of VEGFR-3 in sw480 and HCT116 cells in a dose-dependent manner. Zhang et al. [28] shown that VEGFR-3 were upregulated in macrophages in the endotoxion shock induced by bacteria or LPS. Further research founder that LPS promoted the migration and invasion of colorectal cells but not cells proliferation. This was different from previous reports [29], for this point, we confirmed our cells proliferation experiments used the colorectale formation assay. The reasons for this phenomenon that LPS could not promote the cells proliferation of sw480 and HCT116 required futher investigation.

LPS combinding with TLR4 which is the receptor of LPS can exert the biofunction through its mediation signal pathways. The most very important signal pathway that LPS activates is NF- $\kappa B$ signal pathway. Huang $T$ et al. [13] reported that LPS promoted the progression of breast cancer cells though the NF- $\kappa B$ signal pathway. Zhao et al. [30] revealed that LPS induced tumor angiogenesis also via NF- $\kappa B$ signaling. Zhang et al. [28] found that LPS-TLR4-NF- $\kappa B$ signal promoted the macropahges secretion VEGF. Our experiment results consistent with prevous studies that sw480 and HCT116 cells both express the TLR4. And LPS activated NF- $\kappa B$ making the $p-N F-\kappa B$ increased. So, we speculated that LPS increasing the expression of VEGFR-3 was caused by NF- $\kappa \mathrm{B}$ binding to the promoter of VEGFR-3.

In human, the coding gene transcriptions of many proteins and non-proteins have tissue and cell specificity [31]. And the gene transcription is mostly mediated through the 


\section{Cellular Physiology Cell Physiol Biochem 2016;39:1665-1678 \\ \begin{tabular}{ll|l} 
DOI: 10.1159/000447868 & $\begin{array}{l}\text { O } 2016 \text { The Author(s). Published by S. Karger AG, Basel } \\
\text { www.karger.com/cpb }\end{array}$ \\
\hline
\end{tabular} \\ Zhu et al.: LPS Increased VEGFR-3 Promoting the Migration and Invasion of Colorectal Cancer}

transcription factor that binds to the specific cis element sites in the gene promoter [32]. In the present study, the mechanisms that LPS upregulated VEGFR-3 expression were investigated. We found that -159 nt to +65 nt region was vital to the activity of VEGFR-3 promoter. However, the VEGFR-3 promoter activity had not vanish when we tested the $-59 \mathrm{nt}$ to $+65 \mathrm{nt}$ fragment, therefore merits further investigation. These consistent with other gene promoter study, because promoter activity are decided by lots of transcription factors [33]. To our known, we confirmed that the NF- $\kappa B$ transcription factor regulated the VEGFR-3 expression. And overexpression of NF- $\kappa B$ enhanced the exprssion of VEGFR-3. And LPS upregulated the expression of VEGFR-3 via increasing NF- $\kappa B$ binding to the VEGFR-3 promoter.

In conclusion, this study has demonstrated that the expression of VEGFR-3 in colorectal cancer tissues was markedly higher than the expression in the normal colorectal tissues. Additionally, we provided evidence that LPS contributed to the migration and invasion of sw480 and HCT116 cells but not both cell lines proliferation. We also found that the LPS-

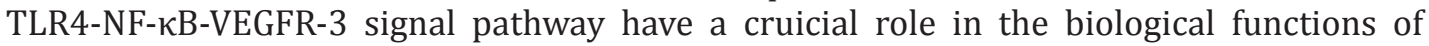
sw480 and HCT116 cells. Futhermore, we in-depth researched the mechanisms of LPS upregulated VEGFR-3 and found that the transcription factor NF- $\kappa B$ play very important role in the aspect of mediated VEGFR-3 promoter activity. Together, our data demonstrated that LPS promote the migration and invasion of colorectal cancer may cause by upregulated VEGFR-3 expression.

\section{Acknowledgements}

This study was supported by the Key Project of Science and Technology Reserch Program in Fujian Province(no. 2012B002),The nursery garden scientific research fund of Fujian medical university(2015MP024), the China Non intervention Gastric Cancer Registration Survey Clinical Research Projects(no. QT-201403), the Ministry of Health Medicine Science and Technology Development and Research(no. W2013FZ08) and the National Clinical Key Specialty Construction Project(General Surgery) of China.

\section{Disclosure Statement}

The authors declare to have no conflicts of interest.

\section{References}

1 Jemal A, Siegel R, Ward E, Hao Y, Xu J, Thun MJ: Cancer statistics, 2009. CA Cancer J Clin 2009;59:225-249.

2 Chen W, Zheng R, Zeng H, Zhang S, He J: Annual report on status of cancer in China, 2011. Chin J Cancer Res 2015;27:2-12.

3 Qin J, Chen JX, Zhu Z, Teng JA: Genistein inhibits human colorectal cancer growth and suppresses miR-95, Akt and SGK1. Cell Physiol Biochem 2015;35:2069-2077.

4 Kobayashi H, Mochizuki H, Sugihara K, Morita T, Kotake K, Teramoto T, Kameoka S, Saito Y, Takahashi K, Hase K, Oya M, Maeda K, Hirai T, Kameyama M, Shirouzu K, Muto T: Characteristics of recurrence and surveillance tools after curative resection for colorectal cancer: a multicenter study. Surgery 2007;141:6775.

5 Mantovani A, Allavena P, Sica A, Balkwill F: Cancer-related inflammation. Nature 2008;454:436-444.

6 Bryant T: Remarks on Some Cases of Inflammation of the Breast Simulating Cancer. Br Med J 1868;2:608609.

7 Coussens LM, Werb Z: Inflammation and cancer. Nature 2002;420:860-867.

8 McMillan DC, Canna K, McArdle CS: The effect of deprivation and the systemic inflammatory response on outcome following curative resection for colorectal cancer. Br J Cancer 2003;89:612-614.

9 Eberhardt JM, Kiran RP, Lavery IC: The impact of anastomotic leak and intra-abdominal abscess on cancerrelated outcomes after resection for colorectal cancer: a case control study. Dis Colon Rectum 2009;52:380386. 
Zhu et al.: LPS Increased VEGFR-3 Promoting the Migration and Invasion of Colorectal Cancer

10 Rakhesh M, Cate M, Vijay R, Shrikant A, Shanjana A: A TLR4-interacting peptide inhibits lipopolysaccharide-stimulated inflammatory responses, migration and invasion of colon cancer SW480 cells. Oncoimmunology 2012;1:1495-1506.

11 Liu X, Liang J, Li G: Lipopolysaccharide promotes adhesion and invasion of hepatoma cell lines HepG2 and HepG2.2.15. Mol Biol Rep 2010;37:2235-2239.

12 Huang LZ, Liu SJ, Zhao JX, Su X, Zhou H, Wang ZL: [CD147 increases invasiveness of U937 cells through regulation of matrix metalloproteinase activity]. Zhongguo Shi Yan Xue Ye Xue Za Zhi 2008;16:247-253.

13 Huang T, Chen Z, Fang L: Curcumin inhibits LPS-induced EMT through downregulation of NF-kappaB-Snail signaling in breast cancer cells. Oncol Rep 2013;29:117-124.

14 Zhao L, Yang R, Cheng L, Wang M, Jiang Y, Wang S: LPS-induced epithelial-mesenchymal transition of intrahepatic biliary epithelial cells. J Surg Res 2011;171:819-825.

15 Iljin K, Karkkainen MJ, Lawrence EC, Kimak MA, Uutela M, Taipale J, Pajusola K, Alhonen L, Halmekyto M, Finegold DN, Ferrell RE, Alitalo K: VEGFR3 gene structure, regulatory region, and sequence polymorphisms. FASEB J 2001;15:1028-1036.

16 Su JL, Yang PC, Shih JY, Yang CY, Wei LH, Hsieh CY, Chou CH, Jeng YM, Wang MY, Chang KJ, Hung MC, Kuo ML: The VEGF-C/Flt-4 axis promotes invasion and metastasis of cancer cells. Cancer Cell 2006;9:209-223.

17 Dhar DK, Naora H, Yamanoi A, Ono T, Kohno H, Otani H, Nagasue N: Requisite role of VEGF receptors in angiogenesis of hepatocellular carcinoma: a comparison with angiopoietin/Tie pathway. Anticancer Res 2002;22:379-386.

18 Poon RT, Lau CP, Cheung ST, Yu WC, Fan ST: Quantitative correlation of serum levels and tumor expression of vascular endothelial growth factor in patients with hepatocellular carcinoma. Cancer Res 2003;63:31213126.

19 Zhu G, Chen X, Wang X, Li X, Du Q Hong H, Tang N, She F, Chen Y: Expression of the RIP-1 gene and its role in growth and invasion of human gallbladder carcinoma. Cell Physiol Biochem 2014;34:1152-1165.

20 Zhu G, Du Q, Wang X, Tang N, She F, Chen Y: TNF-alpha promotes gallbladder cancer cell growth and invasion through autocrine mechanisms. Int J Mol Med 2014;33:1431-1440.

21 Rettino A, Rafanelli F, Genovese G, Goracci M, Cifarelli RA, Cittadini A, Sgambato A: Identification of Sp1 and GC-boxes as transcriptional regulators of mouse Dag1 gene promoter. Am J Physiol Cell Physiol 2009;297:C1113-1123.

22 Wu YL, Peng XE, Wang D, Chen WN, Lin X: Human liver fatty acid binding protein (hFABP1) gene is regulated by liver-enriched transcription factors HNF3beta and C/EBPalpha. Biochimie 2012;94:384-392.

23 Ceelie H, Spaargaren-Van Riel CC, De Jong M, Bertina RM, Vos HL: Functional characterization of transcription factor binding sites for HNF1-alpha, HNF3-beta (FOXA2), HNF4-alpha, Sp1 and Sp3 in the human prothrombin gene enhancer. J Thromb Haemost 2003;1:1688-1698.

24 Valtola R, Salven P, Heikkila P, Taipale J, Joensuu H, Rehn M, Pihlajaniemi T, Weich H, deWaal R, Alitalo K: VEGFR-3 and its ligand VEGF-C are associated with angiogenesis in breast cancer. Am J Pathol 1999;154:1381-1390.

25 Chen Y, Jiang L, She F, Tang N, Wang X, Li X, Han S, Zhu J: Vascular endothelial growth factor-C promotes the growth and invasion of gallbladder cancer via an autocrine mechanism. Mol Cell Biochem 2010;345:77-89.

26 Li R, Younes M, Wheeler TM, Scardino P, Ohori M, Frolov A, Ayala G: Expression of vascular endothelial growth factor receptor-3 (VEGFR-3) in human prostate. Prostate 2004;58:193-199.

27 Witte D, Thomas A, Ali N, Carlson N, Younes M: Expression of the vascular endothelial growth factor receptor-3 (VEGFR-3) and its ligand VEGF-C in human colorectal adenocarcinoma. Anticancer Res 2002;22:1463-1466.

28 Zhang Y, Lu Y, Ma L, Cao X, Xiao J, Chen J, Jiao S, Gao Y, Liu C, Duan Z, Li D, He Y, Wei B, Wang H: Activation of vascular endothelial growth factor receptor-3 in macrophages restrains TLR4-NF-kappaB signaling and protects against endotoxin shock. Immunity 2014;40:501-514.

29 Xing S, Nie F, Xu Q Deng Y, Li W, Yang Z, Zhao X, Zhu P, Wang X, Gao Y, He Z: HDAC is essential for epigenetic regulation of Thy-1 gene expression during LPS/TLR4-mediated proliferation of lung fibroblasts. Lab Invest 2015;95:1105-1116.

30 Zhao K, Song X, Huang Y, Yao J, Zhou M, Li Z, You Q, Guo Q, Lu N: Wogonin inhibits LPS-induced tumor angiogenesis via suppressing PI3K/Akt/NF-kappaB signaling. Eur J Pharmacol 2014;737:57-69.

31 Levine M, Tjian R: Transcription regulation and animal diversity. Nature 2003;424:147-151.

32 Ernst P, Smale ST: Combinatorial regulation of transcription. I: General aspects of transcriptional control. Immunity 1995;2:311-319.

33 Ekstrom L, Lyrenas L, Jakobsson PJ, Morgenstern R, Kelner MJ: Basal expression of the human MAPEG members microsomal glutathione transferase 1 and prostaglandin E synthase genes is mediated by $\operatorname{Sp} 1$ and Sp3. Biochim Biophys Acta 2003;1627:79-84. 